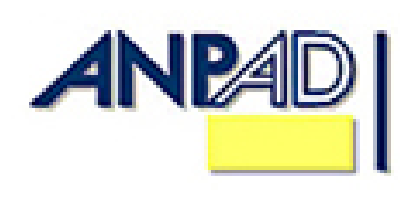

Available online at http://www.anpad.org.br/bar

BAR, Rio de Janeiro, v. 10, n. 2, art. 2, pp. 135-157, Apr./June 2013

\title{
The Equity Premium Puzzle: Analysis in Brazil after the Real Plan
}

Fábio Augusto Reis Gomes E-mail address: fabiogomes@fucape.br Fucape Business School Fucape Business School, Av. Fernando Ferrari, 1358, Vitoria, ES, 29075-505, Brazil.

Luciana de Andrade Costa E-mail address: luciana@fucape.br Fucape Business School Fucape Business School, Av. Fernando Ferrari, 1358, Vitoria, ES, 29075-505, Brazil.

Ruth Carolina Rocha Pupo E-mail address: ruth.pupo@gmail.com Université de Lausanne University of Lausanne, Quartier UNIL-Dorigny Bâtiment Internef, CH-1015 Lausanne, Switzerland.

Received 10 May 2012; received in revised form 8 August 2012; accepted 15 August 2012; published online 13 November 2012. 


\begin{abstract}
Our paper investigates whether there is evidence of an Equity Premium Puzzle (EPP) in Brazil, applying two different methodologies. The EPP was identified by Mehra and Prescott (1985) since the Consumption Capital Asset Pricing Model (CCAPM), when calibrated with reasonable preference parameters, could not explain high historical average risk premiums in the United States. In our first approach, we consider Mehra's (2003) model and calibrate the coefficient of risk aversion, using 1995:2-2012:1 quarterly data. The Ibovespa index was used as a measure of the market return, whereas the risk-free rate was proxied by the Selic interbank rate and by the savings account rate. In our second approach, we propose a new method to test the puzzle. We jointly estimate, via generalized method of moments, the parameters of interest using a moment condition that has not been previously explored, as far as we are aware of. The two approaches produced a high risk aversion coefficient, however the second approach indicated that we cannot reject the hypothesis of the risk aversion coefficient being statistically equal to zero. A possible explanation for this result might be that in Brazil the equity premium is not statistically different from zero. Therefore there is no evidence of EPP in Brazil for the studied period.
\end{abstract}

Key words: Brazil; equity premium puzzle; risk aversion; GMM. 


\section{Introduction}

The intertemporal choice of households and firms concerning how to allocate their resources is of central interest to economics and finance. This decision depends on investment opportunities available and especially on their returns. Mehra and Prescott (1985) investigated the American riskpremium (the difference between market return and United States (U.S.) treasury bill return) in the 1889-1978 period. It is reasonable to think that there should be a premium, given the risk of equity. However, this study became well known for having identified the Equity Premium Puzzle (EPP) for the American economy. Its result suggests that the Consumption Capital Asset Pricing Model (CCAPM), when calibrated with reasonable preference parameters, cannot explain the high historical average risk premiums in the U.S. In other words, a high risk aversion is needed in order to match the theoretical moment from an Arrow-Debreu asset pricing model and the empirical moment.

The purpose of our study is to investigate whether there is evidence of an EPP in Brazil. We take two different approaches in order to check the robustness of our results. We consider the model suggested by Mehra (2003), which uses the CCAPM, with the additional hypothesis that the growth rate of consumption and the gross return on equity are jointly lognormally distributed. This hypothesis allows a more direct investigation of the puzzle, which has not yet been explored in the literature that investigates the EPP in Brazil, as far as we are aware of. The lognormality hypothesis is widely used in finance literature and is especially convenient in our study because it allows us to use two methodologies to obtain the parameter of risk aversion. In the first approach, we obtain the parameter through a calibration exercise, just as Mehra (2003). As far as we are concerned, this is the first application of Mehra's (2003) model to Brazil and constitutes one of the contributions of our paper. Furthermore, differently from Mehra (2003), we also develop another approach which estimates both the coefficient of risk aversion and the two first moments of the growth rate of consumption by means of Generalized Method of Moments (GMM). We estimate a moment condition obtained from the lognormality hypothesis, which, to the best of our knowledge, has not been explored in this way in the literature. With this estimation procedure, we are able to make statistical inference about the risk aversion parameter and, therefore, to check how robust our results are.

Previous studies have examined the EPP in Brazil and did not find evidence of this puzzle, for example Sampaio (2002), Issler and Piqueira (2000), Araújo (2005, 2006), and Samanez and Santos (2007). Using a different methodology, based on the mean-variance frontier, Catalão and Yoshino (2006) also found no puzzle. In contrast, Soriano (2002) found evidence in favor of the EPP, but argues that the magnitude is much smaller than that observed by Mehra and Prescott (1985). In addition, Cysne (2006) also found evidence supporting the puzzle, concluding that the CCAPM is not able to explain the observed risk premium in Brazil.

Although these studies refer to different time periods, none of them incorporates data for 2005 onwards. Furthermore, even those using similar samples, reached different conclusions regarding the existence of the puzzle. In this paper we do not intend to explain or justify these discrepancies, since we start from Mehra (2003) and look for a novel methodology, focusing on the post-Real Plan period. Our goal is to be able to check the robustness of our findings by employing two alternative methodologies having Mehra (2003) as a starting point.

Our study focuses on the post-Real Plan period, avoiding the great instability that existed previously to its implementation. This choice is supported by studies like Samanez and Santos (2007) that found mixed EPP evidence depending on whether the sample included the pre-Real Plan period or not. Therefore, our study uses data from 1995 until the first quarter of 2012, which constitutes another contribution since previous studies have only investigated the EPP in Brazil until 2005. To examine the existence of the EPP in Brazil, we use the Ibovespa as the risky asset and the Selic interest rate ${ }^{(1)}$ and the savings account rate as risk-free returns so as to obtain different measures of the risk premium. We construct the growth rate of consumption using the household final consumption expenditure. 
Finally, the results of our first method, the calibration exercise, did not reject the existence of the EPP in Brazil. The coefficient of risk aversion needed to conciliate the observed and the theoretical (CCAPM) risk premium is greater than 60. Meanwhile, when we use the GMM, the estimated coefficient is still large, but it is not statistically significant. Indeed, additional analyses show that, although the equity premium is positive, it cannot be considered statistically different from zero due to its large variance. In other words, the variance of Ibovespa is large when compared to its average. Thus, we cannot confirm the existence of the EPP in Brazil for the given period. Our conclusion is in line with Issler and Piqueira's research (2000).

This paper is organized as follows. In the second section we review related literature, while in third section we develop the model proposed by Mehra (2003). The fourth section presents the dataset used, as well as the empirical methodology applied. In the fifth section we discuss the results, and, finally, we summarize our conclusions.

\section{Literature Review}

In an attempt to explain the American risk premium over the ninety-year period 1889-1978, Mehra and Prescott (1985) found the EPP. This puzzle is characterized by the fact that, when using the CCAPM, the risk premium could only be replicated with an extremely high coefficient of risk aversion.

Starting from an asset-pricing model with a representative agent, the authors calculated the preference parameters that equated the theoretical risk premium to the historical average. However, using reasonable values of risk aversion, they were not able to reproduce the historical average for the interest rate or the equity premium, which were $0.8 \%$ and $6 \%$, respectively. Therefore these results indicate the existence of the EPP in the U.S. during the period of 1889-1978. It is worth noting that Mehra and Prescott (1985) consider that the puzzle is due in most part to the low average risk-free interest rates, rather than to the high average equity return.

Although Mehra (2003) also discusses the EPP, his paper is not limited to the U.S., but also includes other industrialized countries. Moreover, Mehra (2003) makes the additional assumption that the consumption growth rate and the market return are jointly lognormally distributed. This hypothesis is commonly used in finance and serves, according to Mehra (2003), to simplify the model and the calibration of the preference parameters. The results of Mehra (2003) corroborate the previous results, indicating that the equity premium in the U.S., United Kingdom, Japan, Germany, and France are incompatible with tolerable values for the risk aversion coefficient. We show later that the hypothesis adopted by Mehra (2003) also allows the joint estimation of the two parameters that define the theoretical risk premium: risk aversion and the variance of the consumption growth rate.

Sampaio (2002) and Soriano (2002) were one of the first to replicate the model proposed by Mehra and Prescott (1985) for the Brazilian economy. Sampaio (2002) analyzed the applicability of the CCAPM to the second moments of the financial assets returns. The author uses original and seasonally adjusted data between 1979 and 1998. The use of seasonally adjusted data is justified given that the marginal utilities of individuals may vary with the time of the year. With the original series, Sampaio (2002) found no evidence of the referred puzzle. However, the results changed when using the adjusted series. The coefficient of risk aversion required in order to conciliate the theoretical and the observed risk premium is excessively large. In order to reduce the risk premium, one needs to decrease the discount rate. This mechanism became known as the Inverted Risk Free Puzzle since it is inverse to the one proposed by Mehra and Prescott (1985), which was the Risk Free Puzzle (RFP). The RFP was identified because the theoretical model cannot reproduce the low risk free interest rates observed in the U.S. unless a discount factor greater than one is allowed. 
Soriano (2002) uses data from a similar period as Sampaio (2002), 1980-1998, but applies a different methodology. The author estimates an asset pricing model with a constant relative risk aversion (CRRA) utility function via GMM. The results were submitted to tests based on the stochastic discount frontier. Estimation via GMM generated risk aversion coefficients ranging from 2 to 4 , while the tests based on the stochastic discount frontier produced coefficients greater than 6 . These values still characterize a puzzle, but of a smaller magnitude than the one found for the U.S. by Mehra and Prescott (1985).

Issler and Piqueira (2000) estimate the consumption model for three classes of utility functions: additively separable CRRA, habit formation, and Kreps-Porteus. For the 1975-1994 period, they did not find evidence of the puzzle and this conclusion is robust to the different utility specifications. They argue that there is no EPP due to the absence of a risk premium in Brazil. Issler and Piqueira (2000) show that, even though the coefficient is almost five times greater than the one found for the U.S., its variance is also very large, resulting in a coefficient that is not statistically significant. Conversely, when the American risk premium was submitted to the same test, results indicated a statistically significant coefficient at a $5 \%$ level of significance.

Araújo (2005) extends the work of Soriano (2002) and Issler and Piqueira's (2000), estimating the asset pricing model by GMM using the same three preferences specifications mentioned above. In addition, the author uses Hansen and Jagannathan volatility frontier to test his results and concludes, in most of the cases, that the EPP is non-existent. Furthermore, Araújo (2006) estimates the consumer's preference parameters for the CRRA and the external habit formation cases using the GMM and the information theory, in which the Kullback-Leibler information criterion is minimized. Again, Araújo (2006) found no evidence supporting the puzzle for Brazilian economy over the period from 1974 until 1999.

Nevertheless, Cysne (2006) found the EPP for the period between 1992 and 2004. The author argues that his results are different from the previous ones both because of the data used (the time period is distinct and his consumption series includes durables and non-durable goods), and because of the different methodology applied. Cysne (2006) adopts two approaches to verify whether the EPP is valid in Brazil and in both he fails to reject the existence of the EPP. In the first one, Cysne (2006) assumes that the assets returns have lognormal distribution and calibrates the risk premium. In the second one, the author abandons this hypothesis and calibrates the model by the discrete approximation of the consumption series using 10 states, instead of only 2, as in Sampaio (2002).

Contrary to Cysne (2006), Catalão and Yoshino (2006) found no evidence of the puzzle for the Brazilian economy in the 1991-2003 period, even when separately considering the pre- and post-Real Plan eras. The authors obtain these results using the mean-variance frontier of the stochastic discount factor from the return and premium of the stock market. Their results indicate that it is not possible to identify the EPP since the model cannot generate a valid discount factor and an acceptable coefficient of risk aversion simultaneously.

Samanez and Santos (2007) also apply Mehra and Prescott (1985) model for the Brazilian context in the 1990-2005 period, making the distinction between pre and post Real Plan. The authors found a coefficient of risk aversion close to 5 when considering the entire period, which they argue it does not characterize a puzzle. Moreover, their results show a low intertemporal discount, around 0.8. The authors attribute this to the liquidity constraint faced by many Brazilians who have no access to credit and receive an income close to their subsistence consumption level. Since they have almost no surplus to save, they do not face the possibility of postponing consumption. Due to this constraint, not all individuals consume according to the permanent income hypothesis (PIH).

When restricting the analysis to the first period (1990 to mid-1994), Samanez and Santos (2007) identified the puzzle, since the coefficient of risk aversion required to equate the theoretical and the empirical premium is very high. Moreover, the intertemporal discount factor obtained is very small, being below the limits proposed in the literature. However, when looking at only the second period 
(mid-1994 to 2005), the authors found no evidence of an EPP, which would be due to the greater stability achieved by the Brazilian economy after the Real Plan.

Table 1 provides a summary of the main results from previous studies done for the Brazilian economy. The literature states that the intertemporal discount factor, $\beta$, must lie between 0.5 and 1 (annually); and that the coefficient of risk aversion, $\alpha$, must range between 0 and 10. Some authors like Arrow (1971), Friend and Blume (1975), Kydland and Prescott (1982), and Kehoe (1983), are even stricter and suggest that must lie $\alpha$ between 1 and 2. Thus, although many authors may say they have found no evidence supporting the EPP in Brazil, we can identify in Table 1 high values for $\alpha$, especially if we consider the upper bound of 2 .

Table 1

Results from the Literature

\begin{tabular}{lccc}
\hline \multicolumn{1}{c}{ Study } & $\boldsymbol{\alpha}$ & $\boldsymbol{\beta}^{\text {a }}$ & Conclusion \\
\hline $\begin{array}{l}\text { Issler and Piqueira (2000) } \\
\text { 1975:1 - 1998:4 }\end{array}$ & 4.89 & 0.89 & No evidence of EPP \\
$\begin{array}{l}\text { Sampaio (2002) } \\
\quad \text { Original data } \\
\quad \text { Seasonal adjusted data }\end{array}$ & 6.10 & 0.69 & "Brazilian puzzle"b \\
Soriano (2002) & 33.20 & 0.50 & Evidence of EPP \\
$\quad$ 1980:1 - 1998:4 & $2-6$ & 0.95 & Evidence of EPP \\
$\begin{array}{l}\text { Catalão and Yoshino (2006) } \\
\text { 1991:1 - 2003:3 }\end{array}$ & $2.7-4.5$ & 0.95 & No evidence of EPP \\
$\begin{array}{l}\text { Cysne (2006) } \\
\text { 1992:1-2004:2 }\end{array}$ & 6.0 & 0.97 & Evidence of EPP \\
Samanez and Santos (2007) & & & No evidence of EPP \\
1990:1 - 2005:4 & 5.12 & 0.80 & Evidence of EPP and \\
1990:1 - 1994:2 & 17.22 & 0.07 & Inverted RFP \\
1994:3 - 2005:4 & 1.93 & 0.91 & No evidence of EPP \\
\hline
\end{tabular}

Note. ${ }^{\mathrm{a}} \beta$ is expressed in annual terms; ${ }^{\mathrm{b}}$ As described by Sampaio (2002), equivalent to the inverted RFP in Samanez and Santos (2007).

\section{Model}

The model tested in our study follows Mehra and Prescott (1985) and Mehra (2003), assuming a perfectly competitive market, no credit constraint, and no transaction costs. The representative agent maximizes his time-separable utility function:

$$
E_{t}\left[\sum_{j=0}^{\infty} \beta^{j} U\left(c_{t+j}\right)\right], \quad(0<\beta<1)
$$


where $E_{t}$ is the expectation conditional on all the information publicly available at time $\mathrm{t} ; \beta$ is the intertemporal discount factor, which is the same as $(1+k)^{-1}$, where $k$ is the intertemporal discount rate; $c_{t}$ is per capita consumption; and $U\left(c_{t+j}\right)$ is the agent's utility function.

Additionally, the model assumes a CRRA utility function, which can be written as:

$$
U(c)=\frac{c_{t}^{1-\alpha}-1}{1-\alpha}, 0<\alpha<\infty
$$

where $\alpha$ is the coefficient of relative risk aversion.

The representative agent chooses the share of his income allocated to consumption and to savings in order to maximize his utility. When the individual buys a risky asset, he forgoes $p_{t}$ units of current consumption, which represents a utility loss equivalent to $p_{t} U^{\prime}\left(c_{t}\right)$. By selling this equity in the next period, he can consume $p_{t+1}+y_{t+1}$, where $y_{t+1}$ are the dividends paid at $t+1$. This consumption represents an expected utility gain of $\beta E_{t}\left[\left(p_{t+1}+y_{t+1}\right) U^{\prime}\left(c_{t+1}\right)\right]$. At the optimum level, the utility loss of forgoing current consumption and buying a risky asset must equate the expected discounted utility of the consumption bought in the next period with the selling of the financial asset. We can represent this relationship as:

$$
p_{t} U^{\prime}\left(c_{t}\right)=\beta E_{t}\left[\left(p_{t+1}+y_{t+1}\right) U^{\prime}\left(c_{t+1}\right)\right]
$$

which we can also write as:

$$
1=\beta E_{t}\left[\frac{U^{\prime}\left(c_{t+1}\right)}{U^{\prime}\left(c_{t}\right)} R_{e, t+1}\right]
$$

where $R_{e, t+1}$ is the return on the stock market (risky asset) which is defined as $\left(p_{t+1}+y_{t+1}\right) / p_{t}$. Conversely, for the risk free one period bond, we have:

$$
1=\beta E_{t}\left[\frac{U^{\prime}\left(c_{t+1}\right)}{U^{\prime}\left(c_{t}\right)}\right] R_{f, t+1}
$$

where $R_{f, t+1}=1 / q_{t}$, and $q_{t}$ is the price of the asset. Issler and Piqueira (2000), Soriano (2002), Araújo (2005) and Araújo (2006) apply the GMM to equations similar to (4) and (5).

As in Mehra and Prescott (1985), the return on the risky asset can be written as:

$$
E_{t}\left(R_{e, t+1}\right)=R_{f, t+1}+\operatorname{cov}_{t}\left\{\frac{-U^{\prime}\left(c_{t+1}\right), R_{e, t+1}}{E_{t}\left[U^{\prime}\left(c_{t+1}\right)\right]}\right\}
$$

Thus we can express the equity premium as:

$$
E_{t}\left(R_{e, t+1}\right)-R_{f, t+1}=\operatorname{cov}_{t}\left\{\frac{-U^{\prime}\left(c_{t+1}\right), R_{e, t+1}}{E_{t}\left[U^{\prime}\left(c_{t+1}\right)\right]}\right\}
$$

This expression shows that the risk premium depends on the variance between the marginal utility of consumption and assets returns, meaning that the higher the volatility of the stock market return, the larger the risk premium required by investors.

Mehra (2003) makes some additional hypotheses that we also use in our study, which are:

1. the consumption growth rate, $x_{t+1} \equiv \frac{c_{t+1}}{c_{t}}$ is independent and identically distributed (i.i.d.);

2. the dividends growth at rate $z_{t+1} \equiv \frac{y_{t+1}}{y_{t}}$, which is also i.i.d.; and 
3. $\left(x_{t}, z_{t}\right)$ are jointly lognormally distributed.

Given this, the gross return on equity, $R_{e, t}$, is also i.i.d, and $\left(x_{t}, R_{e, t}\right)$ are jointly lognormally distributed. Therefore, since $U^{\prime}\left(c_{t}\right)=c_{t}^{-\alpha}$, we can show that the gross return on the risk free asset is given by:

$$
R_{f}=\frac{1}{\beta e^{-\alpha \mu_{x}+\frac{1}{2} \alpha^{2} \sigma_{x}^{2}}}
$$

where $\mu_{x}=E[\ln x]$ and $\sigma_{x}^{2}=\operatorname{Var}[\ln x]$ are, respectively, the expectation and the variance of the consumption growth rate. As in Mehra (2003), the risk premium is given by:

$$
\ln E\left(R_{e}\right)-\ln R_{f}=\alpha \sigma_{x}^{2}
$$

From equation (9) we see that the risk premium depends on the variance of the consumption growth rate and on the risk aversion coefficient. If $\sigma_{x}^{2}$ is small, a large risk premium can only be explained by a high degree of risk aversion.

Our first approach is a calibration exercise that consists in selecting the parameter $\alpha$, such that the theoretical risk premium and the historical one are equal. In a second approach, once we estimate $\alpha$, we are able to make statistical inference about it.

\section{Methodology}

As seen in the theoretical model, the difference between the expected return on equity and the risk free asset return depends on the degree of risk aversion, $\alpha$, and on the variance of the consumption growth rate, $\sigma_{x}^{2}$. Thus, to assess the quality of the fit of the model, we need to estimate the latter unknown parameter, taking into account the fact that the expected return on the risky asset is not directly observable. If instead we could observe both of them, the risk aversion coefficient could be easily calibrated by the formula $\alpha=\left[\ln \left(E\left[R_{e, t}\right]\right)-\ln \left(R_{f, t}\right)\right] / \sigma_{x}^{2}$, as in equation (9).

We solve this issue in two distinct ways. First, we apply the methodology proposed by Mehra (2003), where $E\left[R_{e, t}\right]$ is replaced by its historical mean, and $\sigma_{x}^{2}$ is estimated as usual: $\hat{\sigma}_{x}^{2}=$ $\left[\sum_{t=1}^{T}\left(x_{t}-\bar{x}\right)^{2}\right] /(T-1)$, where $\bar{x}=\sum_{t=1}^{T} x_{t} / T$. The second approach is based on GMM estimation. Simply speaking, we can apply this method when there is one moment condition whose expected value is zero, and this moment condition depends on variables that have no unitary root. As we will see, these conditions are met when we rewrite equation (9), and then we can jointly estimate all the parameters of interest.

\section{Data}

The theoretical model suggests that the risk premium depends on the moments of the distribution of consumption growth rate, $\ln \left(x_{t}\right)=\Delta \ln \left(c_{t}\right)$. Therefore, the main variables for the model estimation are the return on the risky and the riskless assets, and the household consumption. As broadly used, the proxy for the return on equity is the return on the Ibovespa, while for the return on the risk free asset we use both the Selic interest rate and the savings rate. The consumption series is the household consumption calculated by the Brazilian Institute of Geography and Statistics (IBGE). We obtain all these series from IPEADATA and deflate using the Extended National Consumer Price Index (IPCA), obtained from the same source. Besides, we divide the real household consumption by the number of residents in Brazil at each year, obtaining per capita real consumption. In turn, consumption growth rate was constructed by taking the difference of the logarithm of per capita real consumption. In Figure 1 we present the histogram and the kernel density for consumption growth rate 
from 1995:2 until 2012:1 $1^{(2)}$. The density was estimated using the Epanechinikov kernel and the Silverman bandwidth.

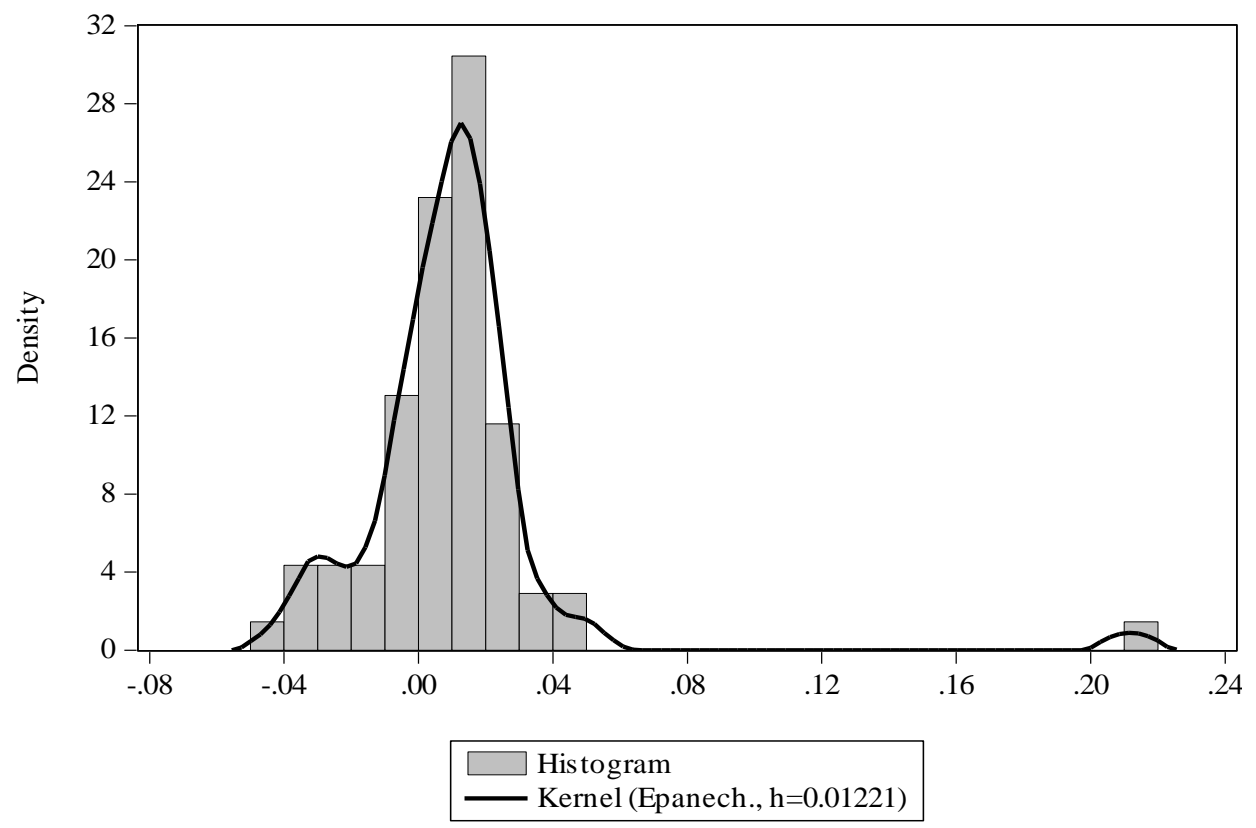

Figure 1. Consumption Growth Rate (1995:1-2012:1).

In order to test whether the consumption growth rate, presented in Figure 1, follows a lognormal distribution, as assumed in Mehra (2003), we conducted a Jarque-Bera (JB) normality test. The test statistic of 2297.437 (p-value lower than 1\%), implies a rejection of the normality null hypothesis. As can be seen in Figure 1, there is an observation in our sample that can be potentially considered an outlier, leading to a rejection of the normal distribution hypothesis. In fact, this observation refers to the consumption growth rate in the first quarter of 1995 and it is likely capturing some residual instability from the period prior to the introduction of the Real Plan. To investigate whether this is true, Figure 2 presents a histogram and the estimated density for the consumption growth rate between 1995:2 and 2012:1 and the normal distribution seems to become suitable. Indeed, the p-value of the JB test statistic becomes greater than $10 \%$. As a result, from this point on, our sample ranges from 1995:2 to $2012: 1$.

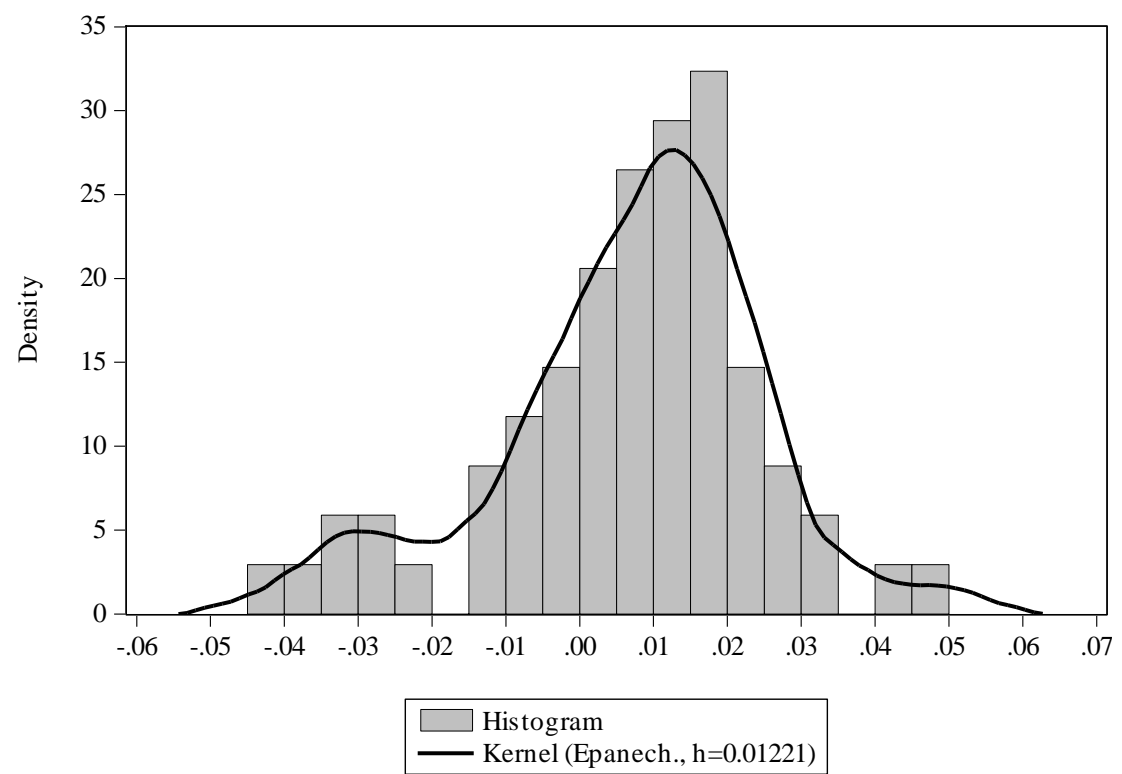

Figure 2. Consumption Growth Rate (1995:2-2012:1). 
Table 2 presents the descriptive statistics for the variables of interest. The mean column shows the average quarterly return, which represents how much an investor (who at each quarter redeems his gains and starts a new investment) gains on average. We can see that the Ibovespa yields on average $4.2210 \%$ per quarter (pq), whereas the risk free assets yield considerably less: $2.7098 \%$ pq and $0.9083 \% \mathrm{pq}$, which are the Selic-gross and savings respectively. Because in Brazil investments opportunities in the fixed income market are subject to a capital gain tax that varies from $15 \%$ to $22.5 \%$ depending on the investment period, we also present two other Selic rates measures, Selic-15\% (85\% of Selic-gross) and Selic-22.5\% (77.5\% of Selic-gross). As can be seen in Table 2, the average values of Selic-15\% and Selic-22.5\% are in-between Savings and Selic-gross. However, in practice, savings and Selic-15\% are, respectively, the lower and the upper bounds for the risk-free return, since some investors have access to the Bank Deposit Certificates (CDB) that almost pay the full Interbank Deposit Certificates (CDI) rate, which follows the Selic interest rate. Therefore, our remarks from now on, as well as our estimation procedure, consider the Selic-15\%, a Selic rate net of $15 \%$ in taxes and we refer to it as simply Selic.

Table 2 also displays information on the risk premium. The difference between the Ibovespa and the Selic is a measure of risk premium and is equal to 2.1741 percentage points ( $\mathrm{pp}$ ). As for the savings, the difference is even bigger, $3.3127 \mathrm{pp}$. By analyzing the standard errors, we can easily see that the Ibovespa volatility is much greater than that of the Selic and the savings. Regarding the consumption growth rate, its average is around zero, while its standard error is noticeably large. Indeed, the coefficient of variation is close to 2.5 .

Table 2

Descriptive Statistics (1995: 2 to 2012:1)

\begin{tabular}{lcc}
\hline Series & Mean & Standard Error \\
\hline Ibovespa (\% p.q.) & 4.2210 & 17.2326 \\
Selic (\% p.q.) - gross & 2.7098 & 1.7724 \\
Selic (\% p.q.) -15\% & 2.0469 & 1.5531 \\
Selic (\% p.q.) - 22.5\% & 1.7154 & 1.4541 \\
Savings (\% p.q.) $_{\text {Risk Premium }}^{\text {a }}$ (pp): Ibovespa-Selic -gross & 0.9083 & 1.3791 \\
Risk Premium $^{\text {a }}$ (pp): Ibovespa-Selic-15\% & 1.5112 & 17.2796 \\
Risk Premium $^{\text {a }}$ (pp): Ibovespa-Selic-22.5\% & 2.1741 & 17.3086 \\
Risk Premium $^{\text {a }}$ (pp): Ibovespa-Savings & 2.5055 & 17.3249 \\
Consumption Growth Rate (\% p.q.) & 3.3127 & 17.3311 \\
\hline
\end{tabular}

Note. ${ }^{\text {a }}$ The risk premium is calculated by taking the difference between the mean of the Ibovespa and of the risk free asset.

Figure 3 shows the time series of Ibovespa, Selic and savings. We can see that the Selic rate is slightly greater than the savings rate. The correlation between them is 0.9117 , and it is statistically different from zero at a $1 \%$ significance level. Meanwhile, the Ibovespa seems to oscillate much more, and presents a smaller correlation of -0.0488 and -0.1076 with the Selic and the savings, respectively. None of them are significant, not even at a $10 \%$ significance level, indicating that both assets (Selic and savings) can be used as riskless assets. 


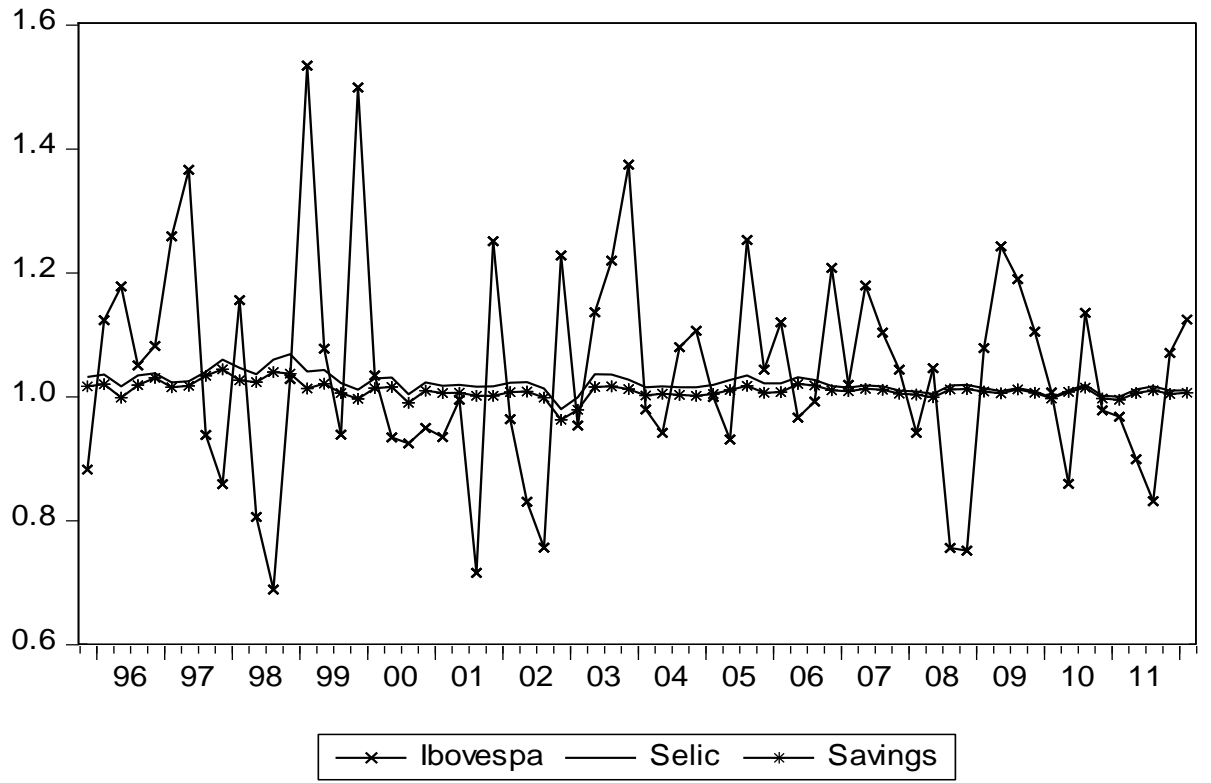

Figure 3. Real Return: Ibovespa, Selic and Savings.

Figure 4 presents the consumption growth rate series. Initially, it fluctuates around zero. However, for more recent observations it is almost always positive. Out of the 68 observations used to construct Figure 4, 49 are positive, while 19 are negative. This is equivalent to say that for each quarter where we see consumption dropping, there are two quarters of consumption growth.

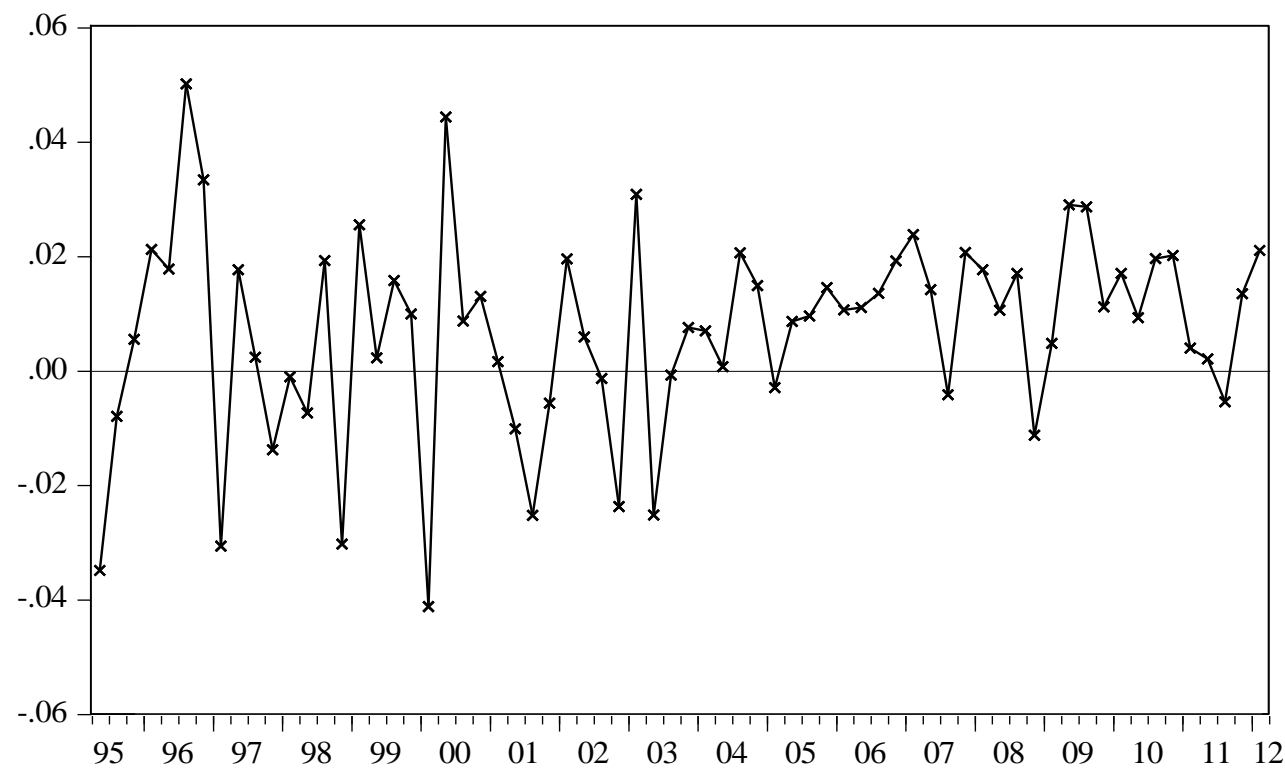

Figure 4. Consumption Growth Rate.

We verify the order of integration of the following variables by using unit root tests: $R_{e, t} / R_{f, t}$ and $\ln \left(x_{t}\right)$. Recall that $\Delta \ln \left(c_{t}\right)$ is the consumption growth rate. Besides, as we show in section Joint estimation by GMM, the ratio between the return on the risky asset and the riskless is one of the variables of the moment condition that we estimate. We use the augmented Dickey-Fuller (ADF) and the Phillips-Perron (PP) tests, where the null hypothesis is that there is at least one unit root (or equivalently, that the series is non-stationary). The tests results are presented in Table 3 . They indicate that the series are not integrated. Therefore, we can proceed to the estimation without making any transformation to the series. 
Table 3

Unit Root Test (1995: 2 to 2012:1)

\begin{tabular}{lcc}
\hline Series & ADF $^{\mathbf{a}}$ & PP $^{\mathbf{b}}$ \\
\hline Ibovespa-Selic Ratio & $-7.9768^{* * *}$ & $-8.0010^{* * *}$ \\
Ibovespa-Savings Ratio & $-7.9451^{* * *}$ & $-7.9578^{* * *}$ \\
Consumption Growth Rate (\% pq) & $-16.7724^{* * *}$ & $-16.3151^{* * *}$ \\
\hline
\end{tabular}

Note. All the estimations include a constant.

${ }^{a}$ We used the Schwarz criterion to choose the number of lags included in the equation for the ADF test; ${ }^{\mathrm{b}}$ The PP test used the Bartlett and the Newey-West window.

$* * * \mathrm{p}<.01 . * * \mathrm{p}<.05 . * \mathrm{p}<.10$.

\section{Calibration exercise}

In a first approach, we follow Mehra (2003) and use equation (9) to calibrate the parameter of risk aversion to obtain:

$$
\alpha=\left[\ln \left(\mathrm{E}\left[\mathrm{R}_{\mathrm{e}, \mathrm{t}}\right]\right)-\ln \left(\mathrm{R}_{\mathrm{f}, \mathrm{t}}\right)\right] / \sigma_{\mathrm{x}}^{2} .
$$

We replace the expected return on equity $E\left[R_{e, t}\right]$, the risk-free asset return $R_{f, t}$, and the variance of the consumption growth rate $\hat{\sigma}_{\mathrm{x}}^{2}$ by their historical values, as shown in Table 2 , in order to obtain the risk aversion coefficient. Since we use both the Selic rate and the savings rate as the risk-free return, we obtain two measures for the risk premium and, therefore, two measures for the risk aversion coefficient.

While this approach gives us an indication of whether there is evidence of an EPP in Brazil, we are not able to test the parameters of interest with regards to their statistical significance. Because of this limitation, we also apply an alternative approach, which estimates the risk aversion coefficient via GMM and allows us to test whether this coefficient is statistically different from zero.

\section{Joint estimation by GMM}

In this section we discuss how we can apply the GMM to estimate $\alpha$, as well as the other parameters, once we assume the log-normality hypothesis.

Let $h\left(Z_{t} ; \theta\right)$ be a model with $r$ equations, where $Z_{t}$ is a $1 \times k$ vector of variables, and $\theta$ a $a \times 1$ vector of parameters. Assume that the system is just or over identified, which means that $r \geq a$. Suppose yet that the variables in $Z_{t}$ are integrated of order zero, and that there is a unique value of $\theta$, say $\theta_{0}$, such that $E\left[h\left(Z_{t} ; \theta_{0}\right)\right]=0$. Given these assumptions, we can apply the GMM to estimate $\theta_{0}$. The method consists of replacing the population moment by the sample moment given by:

$$
g\left(\left\{Z_{t}\right\}_{t=1}^{T} ; \theta\right)=\frac{1}{T} \sum_{t=1}^{T} h\left(Z_{t} ; \theta\right)
$$

In the traditional method of moments, the number of parameters equals the number of moment conditions. Thus we only need to set the sample moments equal to the respective population moments, obtaining the estimates for the parameters. In the GMM, however, we can have an over-identified system, $r>a$, meaning that the number of moment conditions is larger than the number of parameters. In this case, we minimize the quadratic form of the sample moments:

$$
\widehat{\theta}_{M G M}=\operatorname{argmin}\left\{g\left(\left\{Z_{t}\right\}_{t=1}^{T} ; \theta\right){ }^{T} W g\left(\left\{Z_{t}\right\}_{t=1}^{T} ; \theta\right)\right\}
$$


where $W$ is a positive-definite weighting matrix. One can show that the inverse of the asymptotic variance of the sample moment is the optimum choice for this matrix (Hamilton, 1994). For this reason, $W$ becomes a function of $\theta$. In the two-step GMM estimator, $W(\theta)$ is initially set to the identity matrix, yielding the estimator $\hat{\theta}^{(1)}$ and the second step uses $W\left(\hat{\theta}^{(1)}\right)$ in the quadratic form of the sample moments, obtaining $\hat{\theta}_{2 S G M M}$. The iterated GMM estimator continues this process, evaluating $\widehat{W}(\hat{\theta})$ at the previous estimate of $\theta$ until reaching convergence, obtaining $\hat{\theta}_{I G M M}$ (Ferson \& Foerster, 1994). Hansen, Heaton and Yaron (1996) suggested minimizing the following quadratic form of the sample moments:

$$
\hat{\theta}_{C U E}=\operatorname{argmin}\left\{g\left(\left\{Z_{t}\right\}_{t=1}^{T} ; \theta\right)^{\prime} W(\theta) g\left(\left\{Z_{t}\right\}_{t=1}^{T} ; \theta\right)\right\}
$$

where $W(\theta)$ is explicitly a function of $\theta$. This approach was called the continuous-updating estimator, $\hat{\theta}_{C U E}$.

Using the law of iterated expectations, we can re-write equation (9) as:

$$
E\left[\frac{R_{e, t}}{R_{f, t}}-e^{\alpha \sigma_{x}^{2}}\right]=0
$$

This is a moment condition that depends on the risk aversion coefficient and on the variance of consumption growth rate. Replacing $\sigma_{x}^{2}$ by its estimate, we have $r=a=1$, and thus, we can apply the GMM. However, by doing this, we are assuming that $\sigma_{x}^{2}$ is a constant, and thus are ignoring its variability. We should instead jointly estimate $\alpha$ and $\sigma_{x}^{2}$, therefore considering the following moment conditions:

$$
h\left(\ln x_{t}, \frac{R_{e, t}}{R_{f, t}} ; \mu_{x}, \sigma_{x}^{2}, \alpha\right)=\left[\begin{array}{c}
\ln \left(x_{t}\right)-\mu_{x} \\
\left(\ln \left(x_{t}\right)-\mu_{x}\right)^{2}-\sigma_{x}^{2} \\
\frac{R_{e, t}}{R_{f, t}}-e^{\alpha \sigma_{x}^{2}}
\end{array}\right]
$$

The first moment condition estimates the average of $\ln \left(x_{t}\right)$. In turn, this mean is used to estimate the variance of $\ln \left(x_{t}\right)$ in the second moment condition. The variance estimator equals the maximum likelihood estimator. Hence, in spite of being biased, it is a consistent estimator. Consequently, we can identify the degree of risk aversion in the third moment condition. Moreover, we can make statistical inference about the three parameters. Also, as shown in section Data, the variables $\ln \left(x_{t}\right)$ and $R_{e, t} / R_{f, t}$ are not integrated, allowing us to apply the GMM.

Finally, the sample moments are:

$$
g\left(\left\{\ln x_{t}\right\}_{t=1}^{T},\left\{\frac{R_{e, t}}{R_{f, t}}\right\}_{t=1}^{T} ; \mu_{x}, \sigma_{x}^{2}, \alpha\right)=\left[\begin{array}{c}
\frac{1}{T} \sum_{t=1}^{T} \ln x_{t}-\mu_{x} \\
\frac{1}{T} \sum_{t=1}^{T}\left(\ln x_{t}-\mu_{x}\right)^{2}-\sigma_{x}^{2} \\
\frac{1}{T} \sum_{t=1}^{T} \frac{R_{e, t}}{R_{f, t}}-e^{\alpha \sigma_{x}^{2}}
\end{array}\right]
$$

Since the last moment condition is derived from a model which assumes rational expectations, this condition must be orthogonal to any variable that belongs to the consumer information set. For this reason, we can use lagged variables as instruments for that condition. In other words, under the validity of the model, the following additional moment conditions should be valid: $E\left[\left(R_{e, t} / R_{f, t}-\right.\right.$ $\left.\left.e^{\alpha \sigma_{x}^{2}}\right) V_{t-j}\right]=0$, where $j>0$ and $V_{t-j}$ are lagged variables, or instruments, that belong to the consumer information set. With this procedure we can obtain new moment conditions, allowing us to 
employ the $\mathbf{J}$ test of overidentification, where the null hypothesis is that the moment conditions are valid. This test permits us to check the validity of the model, which is an assessment about the auxiliary hypothesis, including, for example, the assumption of lognormality and exogeneity of the instruments.

In the GMM context, instruments are exogenous if they satisfy a conditional mean restriction, $E\left[h\left(Z_{t} ; \theta_{0}\right) V_{t-j}\right]=0$. In our application, this restriction is implied directly by the consumption model above. Although a detailed analysis of instrument exogeneity is expected in an empirical analysis using GMM, another criterion is necessary: instrument relevance. When linear model are estimated by means of IV estimators, the absence of instrument relevance is called the weak instrument problem. Applying GMM to non-linear models, a weak instrument corresponds to weak identification of some or all unknown parameters (Stock, Wright, \& Yogo, 2002).

Under weak identification, the sampling distributions of GMM statistics are in general nonnormal and standard GMM estimates, hypothesis tests, and confidence intervals are unreliable. Hansen et al. (1996) found evidence that GMM-type estimators behave differently in the presence of weak identification. According to them, the continuous updating estimator is less biased, and its confidence intervals have better coverage rates than the two-step GMM. Stock, Wright and Yogo (2002) provide further evidence that weak identification can lead to different confidence sets when the same model is estimated by two-step GMM and iterated GMM, for example. Furthermore, they suggest that weak identification may be verified when GMM estimates are sensitive to additions to the instrument set or to changes in the sample.

By means of Software E-Views 7.0 we apply the GMM estimators using three convergence methods. The first option is the update weights once, then update coefficients once, which is the two-step GMM. The second option is the iterate weights and coefficients sequentially, which repeats the previous method until both coefficients and weighting matrix converge. Lastly, the iterate weights and coefficient simultaneously method is employed, which updates both coefficients and weighting matrix at each iteration. In addition, different instruments sets are used in order to evaluate if results are stable. If so, there is no sign of weak identification.

\section{Results}

The use of quarterly series implies that this is the timing of the representative agent's choice decision. At each quarter, the consumer can reallocate his investments. The risk aversion is linked to the quarterly risk premium, since once the agent has invested in a risky asset, he has to wait three months before being able to change the allocation of his investments. Thus, we should use the averages calculated in Table 2 to proceed with our study.

In a first approach, following Mehra (2003), we use equation (9) to calibrate the parameter of risk aversion so as to obtain $\alpha=\left[\ln \left(\mathrm{E}\left[\mathrm{R}_{\mathrm{e}, \mathrm{t}}\right]\right)-\ln \left(\mathrm{R}_{\mathrm{f}, \mathrm{t}}\right)\right] / \sigma_{\mathrm{x}}^{2}$. As seen in Table 2, the average return on the risky asset is $4.22 \% \mathrm{pq}$, and on the riskless asset is $2.05 \% \mathrm{pq}$ for the Selic, and $0.91 \% \mathrm{pq}$ for the savings. The variance of the consumption growth rate is $\hat{\sigma}_{x}^{2}=0.0003$. Replacing these values in equation (9), we find $\alpha=67.4431$ and $\alpha=103.3383$, when using, respectively, the Selic and savings as the riskless asset.

The values on the risk aversion coefficient are high for both risk free assets, indicating an evidence of EPP. As expected, the risk aversion coefficient when savings is the riskless asset is higher than the one when Selic is the risk free asset. This is corroborated by the fact that the risk premium is higher when savings is used as the riskless asset. This, combined with the same volatility of consumption growth, requires a higher coefficient of risk aversion. Meanwhile, the Ibovespa variability is very high, affecting the variance of its risk premium in the same manner. All this can 
suggest that the high values we found for $\alpha$ may not be significant. Unfortunately, we cannot estimate its standard error and make statistical inference about it using this methodology.

In our second approach, we apply the GMM with the moment conditions we showed in section Joint estimation by GMM. In the first attempt, we estimate the conditions using no instruments. Nevertheless, in this case, the number of parameters equals the number of moment conditions, and this prevents us from performing the $\mathrm{J}$ test. For this reason, we use instruments for the third moment condition. To verify if results are sensitive to the instruments' choice, we consider seven possible instrument sets based on the first and second lags of $R_{e, t} / R_{f, t}$ and $\ln \left(x_{t}\right)$. We only include a few lags because the inclusion of more moment conditions decreases the power of the $\mathrm{J}$ test. Besides, only two observations were lost due to lagged instruments.

The GMM estimation results are presented in Tables 4 to 9. For each riskless asset, we have three convergence methods, summing up to 48 results. Considering all of them, the value obtained for $\mu_{x}$ is very close to the average presented in Table $2(0.0070)$. In Table 2 , we also present the estimate for $\sigma_{x}$, 0.0177 , which when squared becomes 0.0003 , the estimate obtained by GMM in any specification.

The estimates for Selic are displayed in Tables 4, 5 and 6. When the simplest convergence method is used - Table 4 -, the risk aversion ranges from 40-70 and none of the estimates are statistically significant, even at a $10 \%$ significance level. It is worth noting that all tests for overidentifying restrictions had a p-value above 5\%. Thus, we cannot reject the hypothesis that the moment conditions are valid. When the sequential - Table 5 - or the simultaneous - Table 6 convergence method is used the results are very similar and the risk aversion estimates ranges from 36 to 71 , always being statistically not significant. Furthermore, in any case the J-test provides no evidence against the model.

Table 4

GMM Joint Estimation of the Parameters of the System of Equations (11) Using Ibovespa and Selic - Convergence Method: Update Weights Once, then Update Coefficients Once

\begin{tabular}{|c|c|c|c|c|}
\hline Instruments for the equation (10) & $\begin{array}{c}\mu_{x} \\
\text { (p-value) }\end{array}$ & $\begin{array}{c}\sigma_{x}^{2} \\
\text { (p-value) }\end{array}$ & $\begin{array}{c}\alpha \\
\text { (p-value) }\end{array}$ & $\begin{array}{c}\text { J Test } \\
\text { (p-value) }\end{array}$ \\
\hline None & $\begin{array}{c}0.0078 * * * \\
(0.0001)\end{array}$ & $\begin{array}{c}0.0003^{* * *} \\
(0.0000)\end{array}$ & $\begin{array}{l}62.7468 \\
(0.3554)\end{array}$ & \\
\hline$R_{e, t-1} / R_{f, t-1}$ & $\begin{array}{c}0.0078 * * * \\
(0.0002)\end{array}$ & $\begin{array}{c}0.0003 * * * \\
(0.0000)\end{array}$ & $\begin{array}{l}69.4020 \\
(0.3028)\end{array}$ & $\begin{array}{c}0.0088 \\
(0.9253)\end{array}$ \\
\hline $\ln x_{t-1}$ & $\begin{array}{l}0.0081^{* * *} \\
(0.0001)\end{array}$ & $\begin{array}{c}0.0003^{* * *} \\
(0.0000)\end{array}$ & $\begin{array}{l}56.7400 \\
(0.3978)\end{array}$ & $\begin{array}{c}0.0053 \\
(0.9420)\end{array}$ \\
\hline$R_{e, t-1} / R_{f, t-1}, \ln x_{t-1}$ & $\begin{array}{c}0.0080 * * * \\
(0.0001)\end{array}$ & $\begin{array}{c}0.0003 * * * \\
(0.0000)\end{array}$ & $\begin{array}{l}64.0867 \\
(0.3325)\end{array}$ & $\begin{array}{c}0.0115 \\
(0.9943)\end{array}$ \\
\hline$R_{e, t-2} / R_{f, t-2}$ & $\begin{array}{l}0.0079 * * * \\
(0.0001)\end{array}$ & $\begin{array}{l}0.0003^{* * *} \\
(0.0001)\end{array}$ & $\begin{array}{l}40.0068 \\
(0.5473)\end{array}$ & $\begin{array}{c}0.0435 \\
(0.8348)\end{array}$ \\
\hline $\ln x_{t-2}$ & $\begin{array}{l}0.0079 * * * \\
(0.0001)\end{array}$ & $\begin{array}{c}0.0003^{* * *} \\
(0.0000)\end{array}$ & $\begin{array}{l}63.5958 \\
(0.3488)\end{array}$ & $\begin{array}{c}0.0076 \\
(0.9305)\end{array}$ \\
\hline$R_{e, t-2} / R_{f, t-2}, \ln x_{t-2}$ & $\begin{array}{c}0.0079 * * * \\
(0.0001)\end{array}$ & $\begin{array}{c}0.0003^{* * *} \\
(0.0000)\end{array}$ & $\begin{array}{l}41.1272 \\
(0.5347)\end{array}$ & $\begin{array}{c}0.0441 \\
(0.9782)\end{array}$ \\
\hline $\begin{array}{l}R_{e, t-1} / R_{f, t-1}, \ln x_{t-1}, \quad R_{e, t-2} / \\
R_{f, t-2}, \ln x_{t-2}\end{array}$ & $\begin{array}{c}0.0076 * * * \\
(0.0001)\end{array}$ & $\begin{array}{c}0.0003 * * * \\
(0.0000)\end{array}$ & $\begin{array}{l}48.9724 \\
(0.4523)\end{array}$ & $\begin{array}{c}0.0506 \\
(0.9997)\end{array}$ \\
\hline
\end{tabular}

Note. We estimated the weight matrix using the Newey-West estimator with Bartlett kernel. $* * * \mathrm{p}<.01 . * * \mathrm{p}<.05 . * \mathrm{p}<.10$. 
Table 5

GMM Joint Estimation of the Parameters of the System of Equations (11) Using Ibovespa and Selic - Convergence Method: Iterate Weights and Coefficients Sequentially

\begin{tabular}{|c|c|c|c|c|}
\hline Instruments for the equation (10) & $\mu_{x}$ & $\sigma_{x}^{2}$ & $\alpha$ & J Test \\
\hline None & $\begin{array}{l}0.0078^{* * *} \\
(0.0001)\end{array}$ & $\begin{array}{l}0.0003 * * * \\
(0.0000)\end{array}$ & $\begin{array}{l}62.7468 \\
(0.3554)\end{array}$ & \\
\hline$R_{e, t-1} / R_{f, t-1}$ & $\begin{array}{l}0.0078^{* * *} \\
(0.0002)\end{array}$ & $\begin{array}{l}0.0003 * * * \\
(0.0000)\end{array}$ & $\begin{array}{l}70.2758 \\
(0.2934)\end{array}$ & $\begin{array}{c}0.0087 \\
(0.9257)\end{array}$ \\
\hline $\ln x_{t-1}$ & $\begin{array}{c}0.0081 * * * \\
(0.0001)\end{array}$ & $\begin{array}{c}0.0003 * * * \\
(0.0000)\end{array}$ & $\begin{array}{l}56.8388 \\
(0.3910)\end{array}$ & $\begin{array}{c}0.0053 \\
(0.9420)\end{array}$ \\
\hline$R_{e, t-1} / R_{f, t-1}, \ln x_{t-1}$ & $\begin{array}{c}0.0080^{* * *} \\
(0.0001)\end{array}$ & $\begin{array}{c}0.0003^{* * *} \\
(0.0000)\end{array}$ & $\begin{array}{l}64.2627 \\
(0.3236)\end{array}$ & $\begin{array}{c}0.0114 \\
(0.9943)\end{array}$ \\
\hline$R_{e, t-2} / R_{f, t-2}$ & $\begin{array}{c}0.0079 * * * \\
(0.0001)\end{array}$ & $\begin{array}{c}0.0003^{* * * *} \\
(0.0001)\end{array}$ & $\begin{array}{l}36.0129 \\
(0.6202)\end{array}$ & $\begin{array}{c}0.0432 \\
(0.8353)\end{array}$ \\
\hline $\ln x_{t-2}$ & $\begin{array}{l}0.0079 * * * \\
(0.0001)\end{array}$ & $\begin{array}{l}0.0003^{* * *} \\
(0.0000)\end{array}$ & $\begin{array}{l}63.6281 \\
(0.3772)\end{array}$ & $\begin{array}{c}0.0076 \\
(0.9305)\end{array}$ \\
\hline$R_{e, t-2} / R_{f, t-2}, \ln x_{t-2}$ & $\begin{array}{l}0.0079 * * * \\
(0.0001)\end{array}$ & $\begin{array}{l}0.0003 * * * \\
(0.0001)\end{array}$ & $\begin{array}{l}36.6644 \\
(0.6211)\end{array}$ & $\begin{array}{r}0.0439 \\
(0.9783)\end{array}$ \\
\hline $\begin{array}{l}R_{e, t-1} / R_{f, t-1}, \ln x_{t-1}, \quad R_{e, t-2} / \\
R_{f, t-2}, \ln x_{t-2}\end{array}$ & $\begin{array}{c}0.0075^{* * *} \\
(0.0001)\end{array}$ & $\begin{array}{c}0.0003 * * * \\
(0.0000)\end{array}$ & $\begin{array}{l}42.9416 \\
(0.5680)\end{array}$ & $\begin{array}{l}0.0504 \\
(0.9997)\end{array}$ \\
\hline
\end{tabular}

Note. We estimated the weight matrix using the Newey-West estimator with Bartlett kernel.

$* * * \mathrm{p}<.01 . * * \mathrm{p}<.05 . * \mathrm{p}<.10$.

Table 6

GMM Joint Estimation of the Parameters of the System of Equations (11) Using Ibovespa and Selic - Convergence Method: Iterate Weights and Coefficient Simultaneously

\begin{tabular}{lcccc}
\hline Instruments for the equation (10) & $\begin{array}{c}\boldsymbol{\mu}_{\boldsymbol{x}} \\
(\mathbf{p} \text {-value) }\end{array}$ & $\begin{array}{c}\boldsymbol{\sigma}_{\boldsymbol{x}}^{2} \\
(\mathbf{p} \text {-value) }\end{array}$ & $\begin{array}{c}\boldsymbol{\alpha} \\
\text { (p-value) }\end{array}$ & $\begin{array}{c}\text { J Test } \\
\text { (p-value) }\end{array}$ \\
\hline None & $0.0078^{* * *}$ & $0.0003^{* * *}$ & 62.7468 & \\
& $(0.0001)$ & $(0.0000)$ & $(0.3554)$ & \\
$R_{e, t-1} / R_{f, t-1}$ & $0.0078 * * *$ & $0.0003 * * *$ & 70.2759 & 0.0087 \\
& $(0.0002)$ & $(0.0000)$ & $(0.2934)$ & $(0.9257)$ \\
$\ln x_{t-1}$ & $0.0081 * * *$ & $0.0003 * * *$ & 56.8388 & 0.0053 \\
& $(0.0001)$ & $(0.0000)$ & $(0.3910)$ & $(0.9420)$ \\
$R_{e, t-1} / R_{f, t-1}, \ln x_{t-1}$ & $0.0080^{* * *}$ & $0.0003 * * *$ & 64.2627 & 0.0114 \\
& $(0.0001)$ & $(0.0000)$ & $(0.3236)$ & $(0.9943)$ \\
\hline
\end{tabular}


Table 6 (continued)

\begin{tabular}{|c|c|c|c|c|}
\hline Instruments for the equation (10) & $\begin{array}{c}\mu_{x} \\
\text { (p-value) }\end{array}$ & $\begin{array}{c}\sigma_{x}^{2} \\
\text { (p-value) }\end{array}$ & $\begin{array}{c}\alpha \\
\text { (p-value) }\end{array}$ & $\begin{array}{c}\text { J Test } \\
\text { (p-value) }\end{array}$ \\
\hline$R_{e, t-2} / R_{f, t-2}$ & $0.0079 * * *$ & $0.0003 * * *$ & 36.0130 & 0.0432 \\
\hline & $(0.0001)$ & $(0.0001)$ & $(0.6202)$ & $(0.8353)$ \\
\hline $\ln x_{t-2}$ & $0.0079 * * *$ & $0.0003 * * *$ & 63.6279 & 0.0076 \\
\hline & $(0.0001)$ & $(0.0000)$ & $(0.3772)$ & $(0.9305)$ \\
\hline$R_{e, t-2} / R_{f, t-2}, \ln x_{t-2}$ & $0.0079 * * *$ & $0.0003 * * *$ & 36.6647 & 0.0439 \\
\hline & $(0.0001)$ & $(0.0001)$ & $(0.6211)$ & $(0.9783)$ \\
\hline$R_{e, t-1} / R_{f, t-1}, \ln x_{t-1}$ & $0.0075 * * *$ & $0.0003 * * *$ & 42.9418 & 0.0504 \\
\hline$R_{f, t-2}, \ln x_{t-2}$ & $(0.0001)$ & $(0.0000)$ & $(0.5680)$ & $(0.9997)$ \\
\hline
\end{tabular}

Note. We estimated the weight matrix using the Newey-West estimator with Bartlett kernel.

$* * * \mathrm{p}<.01 . * * \mathrm{p}<.05 .{ }^{*} \mathrm{p}<.10$.

The estimates for savings are displayed in Tables 7, 8 and 9. The simplest convergence method - Table 7 - leads to high values for the risk aversion coefficient, ranging from 81 to 110 . This interval becomes 78-110 for the sequential convergence method and 78-111 for the simultaneous method. However, once again, all estimates are not statistically significant, even at a $10 \%$ significance level. Furthermore, the overidentifying restriction test always had a p-value above 5\%. Thus, we cannot reject the hypothesis that the moment conditions are valid.

Table 7

GMM Joint Estimation of the Parameters of the System of Equations (11) Using Ibovespa and Savings - Convergence Method: Update Weights once, then Update Coefficients once

\begin{tabular}{|c|c|c|c|c|}
\hline Instruments for the equation (10) & $\begin{array}{c}\mu_{x} \\
\text { (p-value) }\end{array}$ & $\begin{array}{c}\sigma_{x}^{2} \\
\text { (p-value) }\end{array}$ & $\begin{array}{c}\alpha \\
\text { (p-value) }\end{array}$ & $\begin{array}{c}\text { J Test } \\
\text { (p-value) }\end{array}$ \\
\hline None & $\begin{array}{l}0.0078 * * * \\
(0.0001)\end{array}$ & $\begin{array}{l}0.0003^{* * * *} \\
(0.0000)\end{array}$ & $\begin{array}{l}103.2564 \\
(0.1325)\end{array}$ & \\
\hline$R_{e, t-1} / R_{f, t-1}$ & $\begin{array}{l}0.0077 * * * \\
(0.0002)\end{array}$ & $\begin{array}{l}0.0003 * * * \\
(0.0000)\end{array}$ & $\begin{array}{l}109.7789 \\
(0.1074)\end{array}$ & $\begin{array}{c}0.0097 \\
(0.9215)\end{array}$ \\
\hline $\ln x_{t-1}$ & $\begin{array}{l}0.0082 * * * \\
(0.0000)\end{array}$ & $\begin{array}{l}0.0003^{* * * *} \\
(0.0000)\end{array}$ & $\begin{array}{l}94.3895 \\
(0.1611)\end{array}$ & $\begin{array}{c}0.0072 \\
(0.9324)\end{array}$ \\
\hline$R_{e, t-1} / R_{f, t-1}, \ln x_{t-1}$ & $\begin{array}{l}0.0080^{* * * *} \\
(0.0001)\end{array}$ & $\begin{array}{l}0.0003^{* * * *} \\
(0.0000)\end{array}$ & $\begin{array}{l}102.1248 \\
(0.1235)\end{array}$ & $\begin{array}{c}0.0133 \\
(0.9934)\end{array}$ \\
\hline$R_{e, t-2} / R_{f, t-2}$ & $\begin{array}{l}0.0079 * * * \\
(0.0001)\end{array}$ & $\begin{array}{l}0.0003^{* * * *} \\
(0.0001)\end{array}$ & $\begin{array}{l}81.6920 \\
(0.2246)\end{array}$ & $\begin{array}{c}0.0415 \\
(0.8386)\end{array}$ \\
\hline $\ln x_{t-2}$ & $\begin{array}{l}0.0079 * * * \\
(0.0001)\end{array}$ & $\begin{array}{l}0.0003^{* * * *} \\
(0.0000)\end{array}$ & $\begin{array}{l}106.0061 \\
(0.1218)\end{array}$ & $\begin{array}{c}0.0061 \\
(0.9377)\end{array}$ \\
\hline$R_{e, t-2} / R_{f, t-2}, \ln x_{t-2}$ & $\begin{array}{l}0.0079 * * * \\
(0.0001)\end{array}$ & $\begin{array}{c}0.0003^{* * *} \\
(0.0000)\end{array}$ & $\begin{array}{l}82.5663 \\
(0.2154)\end{array}$ & $\begin{array}{c}0.0417 \\
(0.9794)\end{array}$ \\
\hline $\begin{array}{l}R_{e, t-1} / R_{f, t-1}, \ln x_{t-1}, \quad R_{e, t-2} / \\
R_{f, t-2}, \ln x_{t-2}\end{array}$ & $\begin{array}{l}0.0076^{* * * *} \\
(0.0001)\end{array}$ & $\begin{array}{l}0.0003 * * * \\
(0.0000)\end{array}$ & $\begin{array}{l}91.2448 \\
(0.1615)\end{array}$ & $\begin{array}{c}0.0477 \\
(0.9997)\end{array}$ \\
\hline
\end{tabular}

Note. We estimated the weight matrix using the Newey-West estimator with Bartlett kernel.

$* * * \mathrm{p}<.01 . * * \mathrm{p}<.05 . * \mathrm{p}<.10$. 
Table 8

GMM Joint Estimation of the Parameters of the System of Equations (11) Using Ibovespa and Savings - Convergence Method: Iterate Weights and Coefficients Sequentially

\begin{tabular}{|c|c|c|c|c|}
\hline Instruments for the equation (10) & $\begin{array}{c}\boldsymbol{\mu}_{x} \\
\text { (p-value) }\end{array}$ & $\begin{array}{c}\sigma_{x}^{2} \\
\text { (p-value) }\end{array}$ & $\begin{array}{c}\alpha \\
\text { (p-value) }\end{array}$ & $\begin{array}{c}\text { J Test } \\
\text { (p-value) }\end{array}$ \\
\hline None & $\begin{array}{l}0.0078^{* * *} \\
(0.0001)\end{array}$ & $\begin{array}{c}0.0003 * * * \\
(0.0000)\end{array}$ & $\begin{array}{l}103.2564 \\
(0.1325)\end{array}$ & \\
\hline$R_{e, t-1} / R_{f, t-1}$ & $\begin{array}{l}0.0078^{* * *} \\
(0.0002)\end{array}$ & $\begin{array}{c}0.0003 * * * \\
(0.0000)\end{array}$ & $\begin{array}{l}110.7220 \\
(0.1025)\end{array}$ & $\begin{array}{c}0.0097 \\
(0.9215)\end{array}$ \\
\hline $\ln x_{t-1}$ & $\begin{array}{c}0.0082 * * * \\
(0.0000)\end{array}$ & $\begin{array}{c}0.0003^{* * *} \\
(0.0000)\end{array}$ & $\begin{array}{l}94.5079 \\
(0.1537)\end{array}$ & $\begin{array}{c}0.0071 \\
(0.9328)\end{array}$ \\
\hline$R_{e, t-1} / R_{f, t-1}, \ln x_{t-1}$ & $\begin{array}{l}0.0080^{* * *} \\
(0.0001)\end{array}$ & $\begin{array}{c}0.0003^{* * * *} \\
(0.0000)\end{array}$ & $\begin{array}{l}102.1145 \\
(0.1171)\end{array}$ & $\begin{array}{c}0.0133 \\
(0.9934)\end{array}$ \\
\hline$R_{e, t-2} / R_{f, t-2}$ & $\begin{array}{l}0.0079 * * * \\
(0.0001)\end{array}$ & $\begin{array}{l}0.0003 * * * \\
(0.0001)\end{array}$ & $\begin{array}{l}78.2616 \\
(0.2814)\end{array}$ & $\begin{array}{c}0.0412 \\
(0.8392)\end{array}$ \\
\hline $\ln x_{t-2}$ & $\begin{array}{c}0.0079 * * * \\
(0.0001)\end{array}$ & $\begin{array}{l}0.0003 * * * \\
(0.0000)\end{array}$ & $\begin{array}{l}106.1877 \\
(0.1418)\end{array}$ & $\begin{array}{c}0.0061 \\
(0.9377)\end{array}$ \\
\hline$R_{e, t-2} / R_{f, t-2}, \ln x_{t-2}$ & $\begin{array}{l}0.0079 * * * \\
(0.0001)\end{array}$ & $\begin{array}{l}0.0003 * * * \\
(0.0000)\end{array}$ & $\begin{array}{l}79.2061 \\
(0.2791)\end{array}$ & $\begin{array}{c}0.0415 \\
(0.9795)\end{array}$ \\
\hline $\begin{array}{l}R_{e, t-1} / R_{f, t-1}, \ln x_{t-1}, \quad R_{e, t-2} / \\
R_{f, t-2}, \ln x_{t-2}\end{array}$ & $\begin{array}{c}0.0076^{* * *} \\
(0.0001)\end{array}$ & $\begin{array}{l}0.0003 * * * \\
(0.0000)\end{array}$ & $\begin{array}{l}86.6134 \\
(0.2390)\end{array}$ & $\begin{array}{c}0.0475 \\
(0.9997)\end{array}$ \\
\hline
\end{tabular}

Note. We estimated the weight matrix using the Newey-West estimator with Bartlett kernel.

$* * * \mathrm{p}<.01 . * * \mathrm{p}<.05 . * \mathrm{p}<.10$.

Table 9

GMM Joint Estimation of the Parameters of the System of Equations (11) Using Ibovespa and Savings - Convergence Method: Iterate Weights and Coefficient Simultaneously

\begin{tabular}{|c|c|c|c|c|}
\hline Instruments for the equation (10) & $\begin{array}{c}\boldsymbol{\mu}_{x} \\
\text { (p-value) }\end{array}$ & $\begin{array}{c}\sigma_{x}^{2} \\
\text { (p-value) }\end{array}$ & $\begin{array}{c}\alpha \\
\text { (p-value) }\end{array}$ & $\begin{array}{c}\text { J Test } \\
\text { (p-value) }\end{array}$ \\
\hline \multirow[t]{2}{*}{ None } & $0.0078 * * *$ & $0.0003 * * *$ & 103.2564 & \\
\hline & $(0.0001)$ & $(0.0000)$ & $(0.1325)$ & \\
\hline \multirow[t]{2}{*}{$R_{e, t-1} / R_{f, t-1}$} & $0.0078 * * *$ & $0.0003 * * *$ & 110.7220 & 0.0097 \\
\hline & $(0.0002)$ & $(0.0000)$ & $(0.1025)$ & $(0.9215)$ \\
\hline \multirow[t]{2}{*}{$\ln x_{t-1}$} & $0.0082 * * *$ & $0.0003 * * *$ & 94.5080 & 0.0071 \\
\hline & $(0.0000)$ & $(0.0000)$ & $(0.1537)$ & $(0.9328)$ \\
\hline \multirow[t]{2}{*}{$R_{e, t-1} / R_{f, t-1}, \ln x_{t-1}$} & $0.0080 * * *$ & $0.0003 * * *$ & 102.1142 & 0.0133 III \\
\hline & $(0.0001)$ & $(0.0000)$ & $(0.1172)$ & (0.9934) \\
\hline
\end{tabular}


Table 9 (continued)

\begin{tabular}{|c|c|c|c|c|}
\hline Instruments for the equation (10) & $\begin{array}{c}\mu_{x} \\
\text { (p-value) }\end{array}$ & $\begin{array}{c}\sigma_{x}^{2} \\
\text { (p-value) }\end{array}$ & $\begin{array}{c}\alpha \\
\text { (p-value) }\end{array}$ & $\begin{array}{c}\text { J Test } \\
\text { (p-value) }\end{array}$ \\
\hline$R_{e, t-2} / R_{f, t-2}$ & $\begin{array}{l}0.0079 * * * \\
(0.0001)\end{array}$ & $\begin{array}{l}0.0003^{* * * *} \\
(0.0001)\end{array}$ & $\begin{array}{l}78.2634 \\
(0.2815)\end{array}$ & $\begin{array}{c}0.0412 \\
(0.8392)\end{array}$ \\
\hline $\ln x_{t-2}$ & $\begin{array}{l}0.0079 * * * \\
(0.0001)\end{array}$ & $\begin{array}{l}0.0003^{* * *} \\
(0.0000)\end{array}$ & $\begin{array}{l}106.1875 \\
(0.1418)\end{array}$ & $\begin{array}{l}0.0061 \\
(0.9377)\end{array}$ \\
\hline$R_{e, t-2} / R_{f, t-2}, \ln x_{t-2}$ & $\begin{array}{l}0.0079 * * * \\
(0.0001)\end{array}$ & $\begin{array}{l}0.0003^{* * *} \\
(0.0000)\end{array}$ & $\begin{array}{l}79.2045 \\
(0.2789)\end{array}$ & $\begin{array}{l}0.0415 \\
(0.9795)\end{array}$ \\
\hline $\begin{array}{l}R_{e, t-1} / R_{f, t-1}, \ln x_{t-1}, \quad R_{e, t-2} / \\
R_{f, t-2}, \ln x_{t-2}\end{array}$ & $\begin{array}{l}0.0076^{* * * *} \\
(0.0001)\end{array}$ & $\begin{array}{l}0.0003 * * * \\
(0.0000)\end{array}$ & $\begin{array}{l}86.6137 \\
(0.2390)\end{array}$ & $\begin{array}{c}0.0475 \\
(0.9997)\end{array}$ \\
\hline
\end{tabular}

Note. We estimated the weight matrix using the Newey-West estimator with Bartlett kernel.

$* * * \mathrm{p}<.01 . * * \mathrm{p}<.05 .{ }^{*} \mathrm{p}<.10$.

The results for the risk aversion coefficient are all above the lowest upper limit of 10, which is compatible with a high risk premium. However, none of the estimates for the risk aversion coefficient are statistically significant. These results are robust in the sense that different convergence methods and instrument sets lead to the same conclusion about the coefficient of relative risk aversion as well as the other parameters. Given that instability is a symptom of weak identification, our estimations do not seem to be suffering from this issue.

Our conclusion about the risk premium is in line with Issler and Piqueira's (2000) findings. The authors suggest that, in Brazil, the Ibovespa is highly volatile and that the risk premium, although extremely high at certain points in time, it is not statistically different from zero. Some other authors, like Gonçalves, Rochaman, Eid and Chalela (2011), also point to the high volatility and the intertemporal inconsistency of the risk premium as characteristics of the Brazilian equity market. To sum up, we find that the risk premium is often high, which requires a large risk aversion coefficient. However, due to the high volatility of the Ibovespa, the risk premium is not statistically significant, implying the same for the risk aversion coefficient.

To further investigate our findings, we estimate the following model via Ordinary Least Squares (OLS): Risk Premium $=\mu+$ error, where $\mu$ is a constant term that indicates whether the premium is positive or negative on average. In case $\mu$ is statistically different from zero, the average risk premium is not statistically equal to zero. Since the consumer bases his decision on the expected return of the risky asset, we estimate the expected value of the Ibovespa using its historical average in the following way: the expected return on the Ibovespa at period $t$ equals the average return from 1991:1 until period $t-1$. We calculate the risk premium as the difference, in percentage points, between the returns on the risky (when possible the Ibovespa, otherwise, we use its forecast) and on the riskless assets (both Selic and savings). We present these results in Table 10.

As shown in Table 10, the estimates for $\mu$ are always positive, implying that on average the risk premium is positive. Finally, when we use the actual Ibovespa, the OLS estimate is not statistically different from zero, either with Selic or with savings. Nevertheless, when we use the forecast for Ibovespa, the result is reversed. We reject the null hypothesis that $\mu$ is equal to zero at a $1 \%$ significance level. 
Table 10

OLS Estimation of the Model: Risk Premiu $=\mu+$ error

\begin{tabular}{lcccc}
\hline Risky Asset & Riskless Asset & Coef. & Std. Error & P-value \\
\hline Actual Ibovespa $^{\text {Ibovespa }- \text { Historical Average }}{ }^{\mathrm{a}}$ & Selic & 2.1741 & 2.0311 & 0.2883 \\
Actual Ibovespa $^{\text {Ibovespa }- \text { Historical Average }}{ }^{\mathrm{a}}$ & Selic & $8.0976^{* * *}$ & 0.4934 & 0.0000 \\
\hline
\end{tabular}

Note. Standard errors were estimated using the Newey-West estimator with Bartlett kernel.

${ }^{a}$ The historical average refers to the Ibovespa projection with the growing window from 1991:1 up to the last quarter forecasted.

$* * * \mathrm{p}<.01 . * * \mathrm{p}<.05 . * \mathrm{p}<.10$.

The results differ when we use Ibovespa projections, for two reasons. First, the average forecast is greater than the actual average. Thus, when we use the projection, the risk premium becomes larger. Second, the variability of Ibovespa is higher than that of its forecast. This becomes evident by looking at Figure 5. The standard error of Ibovespa (17.23) is approximately six times greater than the one of its forecast (2.90). The fact that the volatility of a financial asset is so distinct from that of its forecast explains why it is so difficult to predict the Ibovespa return.

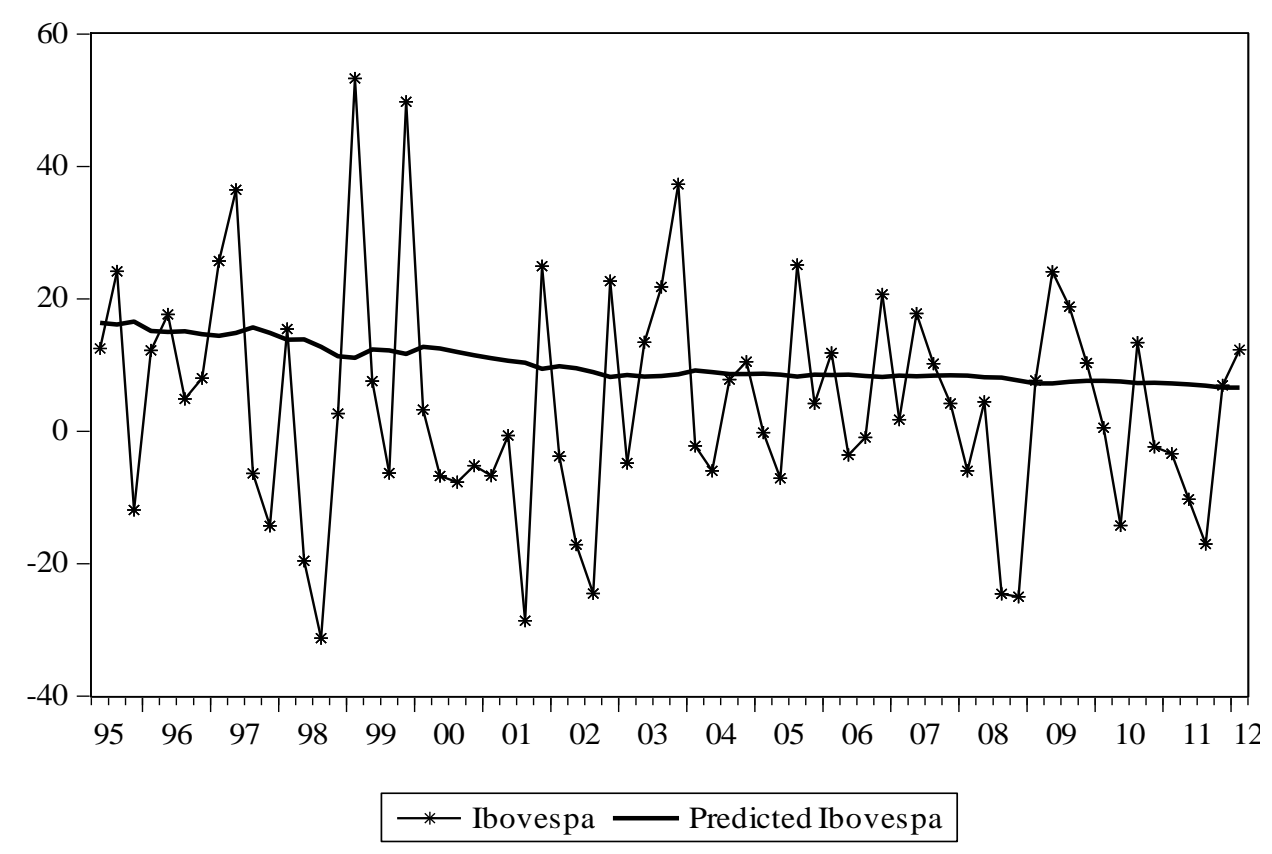

Figure 5. Ibovespa and Predicted Ibovespa.

Finally, our results are in line with the conclusion drawn by Issler and Piqueira (2000). Ex-post, that Ibovespa volatility is so high that it implies a risk premium statistically equal to zero, however, ex-ante, the expected risk premium is positive. 


\section{Conclusion}

The purpose of our study is to test the EPP during the post-Real Plan period based on the model proposed by Mehra (2003), and considering two alternative methodologies to obtain the parameter of risk aversion.

In our first approach, the calibration exercise, we conclude that there is strong evidence supporting the EPP. In our second approach, the GMM estimation, the results are similar to the ones from the calibration exercise, however the risk aversion coefficients are not statistically significant. More precisely, when we estimate the parameters via GMM, the estimates for $\alpha$ are very large, indicating a high risk premium, however we cannot say that the coefficient of risk aversion is statistically different from zero. The non-validity of the EPP in Brazil corroborates the results obtained in Catalão and Yoshino (2006), and Samanez and Santos (2007), for example.

Issler and Piqueira (2000) also conclude that there is no evidence of puzzle in the Brazilian economy. In addition, they identify that this is due to the absence of a risk premium in the equity market. The authors claim that the risk premium is considerably high in several periods, but it is not statistically significant. We use a model to verify this argument. We find that when we use the actual Ibovespa as the risky asset, its variability implies that the risk premium is not statistically different from zero. When we use the historical forecast for the Ibovespa, the risk premium remains positive and significant.

Authors used different propositions to justify the EPP in the US since the study of Mehra and Prescott (1985). A summary of these explanations can be found in Mehra's work (2003), which advocates that the main solutions to the puzzle relate to: the structure of consumers' preferences, such as habit formation; the asset's specific risk and the risk of not having income in the future; the probability of a sharp change in consumption and the survivorship bias ${ }^{(3)}$; the credit constraint; the liquidity premium; the tax rates; and even the absence of a risk premium depending on the time horizon considered.

For Brazil, there is wide evidence that the credit constraint plays an important role in the consumption decision for most part of the population (Gomes, Issler, \& Salvato, 2005; Gomes \& Paz, 2010; Reis, Issler, Blanco, \& Carvalho, 1998). Hence, it would be interesting to further investigate the possible effects of credit constraint on the EPP in Brazil.

\section{Notes}

\footnotetext{
${ }^{1}$ Selic interest rate is the rate for overnight interbank loans that have federal government bonds as collateral. The Brazil Central Bank sets a target for the Selic rate in order to guarantee inflation rate meets its target, as defined by the National Monetary Council (CMN).

${ }^{2}$ Only when we calculate the historical average of Ibovespa in Table 10 do we consider a longer period of time, starting in 1991:1. This is necessary to guarantee that the historical Ibovespa average in the beginning of our sample would be calculated using a reasonable period of time.

${ }^{3}$ Survivorship bias regards the bias that can be caused by achievements of funds, when other funds of low performance are incorporated to contrive the performance of the later ones.
} 


\section{References}

Araújo, E. A., Jr. (2005). Avaliando três especificações para o fator de desconto estocástico através da fronteira de volatilidade de Hansen-Jaganathan: um estudo empírico para o Brasil. Pesquisa e Planejamento Econômico, 35(1), 49-73.

Araújo, E. A., Jr. (2006). Avaliação e teste de dois modelos de formação de preço de ativos baseados no consumo para o Brasil: uma abordagem baseada em teoria da informação. Brazilian Business Review, 3(1), 1-14.

Arrow, K. J. (1971). Essays in the theory of risk-bearing. Amsterdam: North-Holland

Catalão, A. B., \& Yoshino, J. A. (2006). Fator de desconto estocástico no mercado acionário brasileiro. Estudos Econômicos, 36(3), 435-463. doi: 10.1590/S0101-41612006000300002

Cysne, R. P. (2006). Equity-premium puzzle: evidence from Brazilian data. Economia Aplicada, 10(2), 161-180. doi: 10.1590/S1413-80502006000200001

Ferson, W., \& Foerster, S. (1994). Finite sample properties of the generalized method of moments in tests of conditional asset pricing models. Journal of Financial Economics, 36(1), 29-55. doi: $10.1016 / 0304-405 X(94) 90029-9$

Friend, I., \& Blume, M. E. (1975). The demand for risky assets. American Economic Review, 65(5), 900-922.

Gomes, F. A. R., Issler, J. V., \& Salvato, M. A. (2005). Principais características do consumo de duráveis no Brasil e testes de separabilidade entre duráveis e não-duráveis. Revista Brasileira de Economia, 59(1), 33-60. doi: 10.1590/S0034-71402005000100002

Gomes, F., \& Paz, L. (2010). Consumption in South America: myopia or liquidity constraints? Economia Aplicada, 14(2), 129-145. doi: 10.1590/S1413-80502010000200001

Gonçalves, W., Jr., Rochman, R. R., Eid, W., Jr., \& Chalela, L. R. (2011). Estimando o prêmio de mercado brasileiro. Revista de Administração Contemporânea, 15(5), 931-954. Retrieved from http://www.anpad.org.br/periodicos/arq_pdf/a_1237.pdf. doi: 10.1590/S141565552011000500009

Hamilton, J. D. (1994). Time series analysis. Durham, NC: Princeton University Press.

Hansen, L. P., Heaton, J., \& Yaron, A. (1996). Finite sample properties of some alternative GMM Estimators. Journal of Business \& Economic Statistics, 14(3), 262-280. doi: 10.2307/1392442

Issler, J. V., \& Piqueira, N. S. (2000). Estimating relative risk aversion, the discount rate, and the intertemporal elasticity of substitution in consumption for Brazil using three types of utility functions. Brazilian Review of Econometrics, 20(2), 201-239.

Kehoe, P. J. (1983). Dynamics of the current account: theoretical and empirical analysis [Working paper]. Harvard University, Cambridge, MA.

Kydland, F. E., \& Prescott, E. C. (1982). Time to build and aggregate fluctuations. Econometrica, 50(6), 1345-1370.

Mehra, R. (2003). The equity premium: why is it a puzzle? Financial Analysts Journal, 59(1), 54-69. doi: 10.2469/faj.v59.n1.2503

Mehra, R., \& Prescott, E. C. (1985). The equity premium: a puzzle. Journal of Monetary Economics, 15(2), 145-161. doi: 10.1016/0304-3932(85)90061-3 
Reis, E., Issler, J. V., Blanco, F., \& Carvalho, L. M. (1998). Renda permanente e poupança precaucional: evidências empíricas para o Brasil no passado recente. Pesquisa e Planejamento Econômico, 28(2), 233-272.

Samanez, C. P., \& Santos, R. C. (2007). Análise e avaliação do equity premium puzzle no mercado acionário brasileiro sob diferentes contextos econômicos. Revista Brasileira de Economia de Empresas, 7(2), 29-41.

Sampaio, F. S. (2002). Existe equity premium puzzle no Brasil? In M. Bonomo (Ed.), Finanças aplicadas ao Brasil (pp. 87-117). Rio de Janeiro: Editora FGV.

Soriano, A. (2002). Testando o CCAPM através das fronteiras de volatilidade e da equação de Euler. In M. Bonomo (Ed.), Finanças aplicadas ao Brasil (pp. 121-161). Rio de Janeiro: Editora FGV.

Stock, J. H., Wright, J. H., \& Yogo, M. (2002). A survey of weak instruments and weak identification in generalized method of moments. Journal of Business and Economic Statistics, 20(4), 518529. doi: 10.1198/073500102288618658 